\title{
REMED: una red de colaboración para implantar estrategias digitales en los museos
}

\begin{abstract}
En marzo de 2020 se creaba la Red de Museos y Estrategias Digitales, REMED, una red colaborativa online de profesionales de museos creada para adaptar las metodologías de los museos e instituciones culturales al nuevo paradigma digital. Y en su primer cumpleaños, el pasado marzo, REMED celebraba el I Congreso Internacional de Museos y Estrategias Digitales-CIMED dirigido a la comunidad hispanohablante con más de 400 asistentes. La finalidad: debatir y conocer los retos a los que se enfrentan los museos, las posibles soluciones a su adaptación digital, contando para ello con un marco donde compartir experiencias y transferir conocimiento.
\end{abstract}

Adolfo Muñoz García, Ana Martí Testón | Dpto. de Comunicación Audiovisual, Documentación e Historia del Arte, Universitat Politècnica de València

URL de la contribución <http://www.iaph.es/revistaph/index.php/revistaph/article/view/4933>

\section{¿Qué es REMED?}

La Red de Museos y Estrategias Digitales REMED es una asociación profesional sin ánimo de lucro que nació en marzo de 2020, en pleno confinamiento por la COVID-19, para dar soporte a la investigación, documentación y exposición de los procesos de adaptación a un nuevo contexto digital marcado por el obligatorio cierre de las salas en todo el país. El principal objetivo de REMED es garantizar la misión de los museos y acompañarlos en la transformación digital, facilitando soluciones y experiencias a la geografía hispanohablante. Pero más allá del territorio español, nos encontramos con asociados oriundos de Portugal, Argentina, Brasil, México, Chile, Ecuador, Colombia, Perú, Cuba y Honduras, e incluso de universidades y empresas de EE.UU., Inglaterra, Canadá, Alemania, Bolivia, Nigeria, Polonia y Rusia.

En abril de 2021, después de un año de recorrido, la red cuenta ya con 800 socios de varias nacionalidades, eminentemente de habla hispana. En su mayor parte se trata de profesionales de museos, instituciones culturales, universidades y empresas. Los perfiles más frecuentes son museólogos/as, comisarios/as, conservadores/ as, directores/as de museos, educadores/as, académicos/as, investigadores/as, docentes, analistas, gestores/ as culturales, guías de museos y mediadores/as.

\section{Los orígenes de la red de profesionales}

Si tuviéramos que rememorar los primeros pasos de lo que ahora es la red, tendríamos que decir que antes de convertirse en una asociación de profesionales de museos e investigadores fue, sobre todo, el producto de un gesto espontáneo de un puñado de profesores de la Universitat Politècnica de València al comprobar que estábamos obligados a recluirnos en casa, a cerrar persianas y olvidarnos por un periodo de tiempo indefinido de la vida cultural, tal y como la conocíamos hasta ese momento. Fue un acto reflejo de ayuda hacia los profesionales de los museos desde el estamento universitario, sabedores de que en tiempos de reclusión las

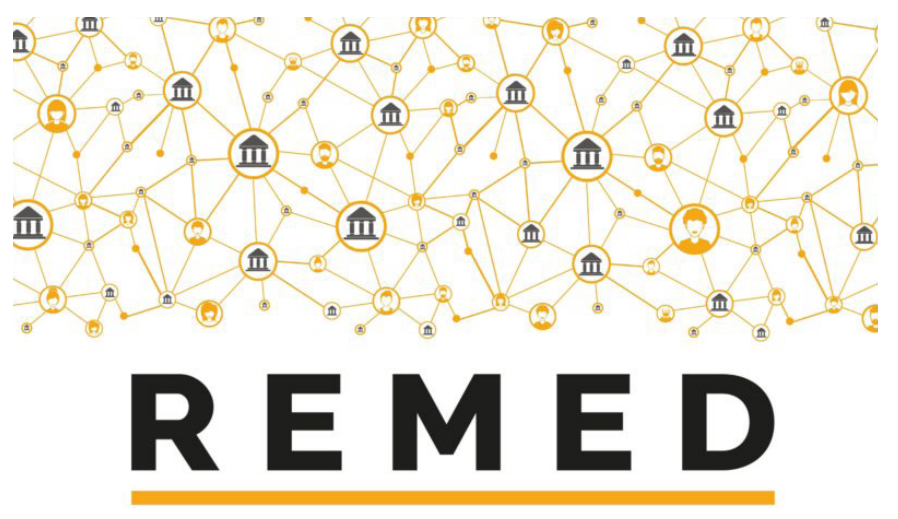

RED DE MUSEOS Y ESTRATEGIAS DIGITALES 


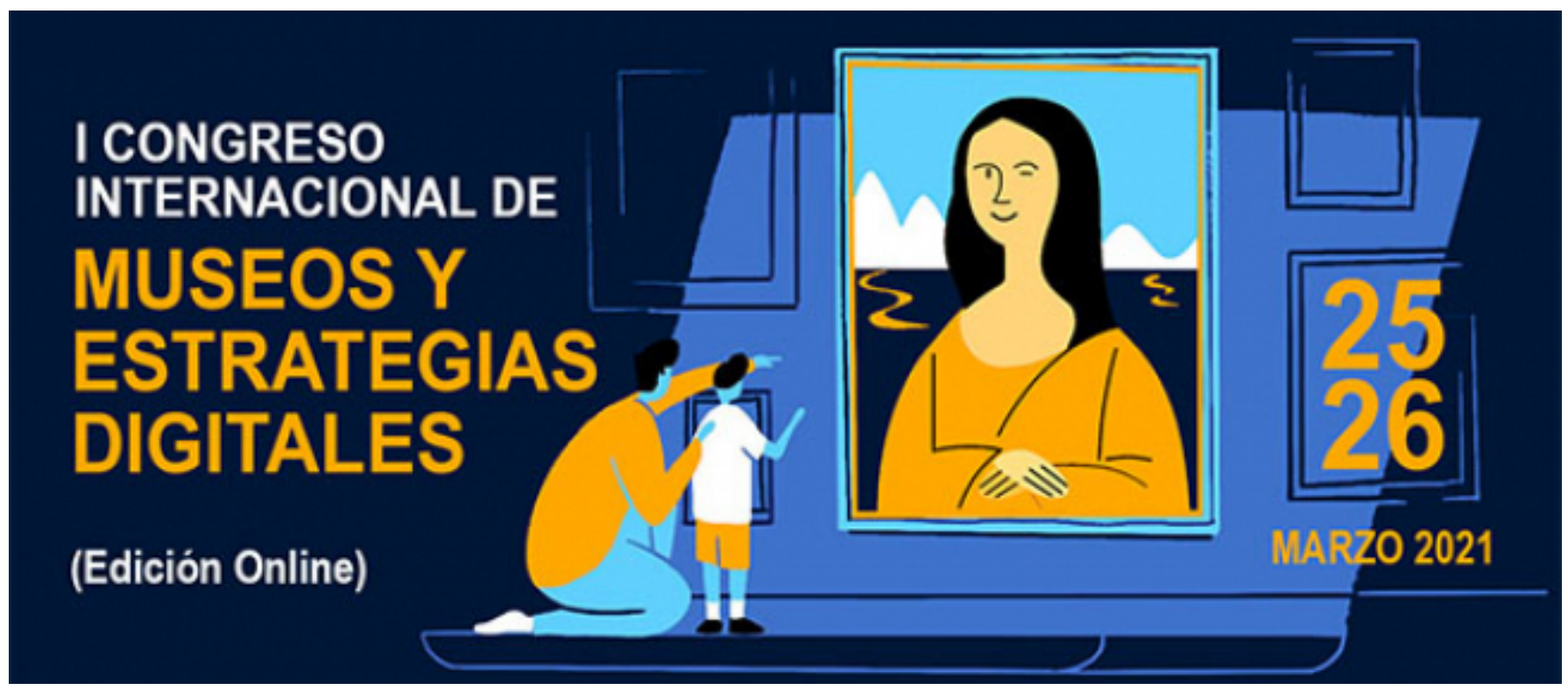

Cartel del primer encuentro organizado por REMED

tecnologías de la comunicación podrían abrir una puerta de esperanza, o al menos, una vía de desahogo entre colegas que comparten las mismas inquietudes y temores sobre el futuro de los museos.

Para nuestra sorpresa este primer tímido impulso dado por un puñado de profesores con la colaboración de alumnos del máster en Gestión Cultural y del programa de doctorado en Industrias Culturales, se convirtió en muy poco tiempo en una enorme ola, cuando el boca a boca y mail a mail fue difundiendo la existencia de REMED: un lugar de contacto para profesionales de museos donde poder compartir experiencias con otros colegas sobre el estado de su museo, sus problemas y sus ideas para abrirse a un nuevo público digital online. Y es que tanto el público que solía pisar los pasillos y deambular por las salas, como los profesionales de los museos, se vieron obligados a adentrarse en un territorio para muchos nuevo, donde los paseos son virtuales y los espacios están formados por píxeles.

En REMED, al principio las reuniones online fueron programadas semanalmente, pasando a ser quincenales para poder preparar sesiones temáticas específicas, para tratar temas candentes con especialistas invitados en los que denominamos VIERNES REMED. Hemos de subrayar la colaboración totalmente altruista de estos profesionales, sin olvidarnos tampoco de la labor desinteresada de los alumnos de la UPV y la UV, involucrados en este proyecto, que han ayudado con toda la logística necesaria para mantener y organizar un grupo de socios cada día más numeroso.

A partir de las experiencias desarrolladas desde la red REMED y las reuniones de los viernes, decidimos emprender una iniciativa necesaria en el contexto hispanohablante: preparar un Congreso Internacional sobre Museos y Estrategias Digitales para 2021, el primer CIMED. Este encuentro finalmente congregó de forma online a 400 personas durante los días 25 y 26 de marzo, y fue precedido de tres días de talleres donde se trataron temas prácticos en grupos reducidos, como la preparación de una estrategia digital, el uso de las redes sociales, los videojuegos o la realidad aumentada.

Así pues, podemos decir que REMED y el Congreso CIMED atienden la imperiosa necesidad de compartir experiencias que nos ayuden a salir de esta crisis, para poder asimilar el cambio de paradigma que se ha hecho obvio durante estos meses: que el mundo digital está aquí para quedarse y que seguirá transformando cada vez más nuestras vidas y por supuesto, nuestros museos. 
Resulta ya obvio que las relaciones sociales primero, y la forma de disfrutar de la cultura se han visto catapultadas hacia un plano digital, donde lo que debería primar no es tanto el conocimiento tecnológico como la emoción. Es alrededor de la emoción, y no exclusivamente de la tecnología, donde podemos construir experiencias nuevas que nos involucren personalmente, más allá de modas o tendencias pasajeras. Es también la emoción la que nos ha guiado en la construcción de esta comunidad horizontal de apoyo y conocimiento que es REMED. Por ello tuvimos claro desde el principio el papel fundamental de crear sesiones periódicas de videoconferencias, y hacer de éstas el pilar de nuestra comunicación grupal.

\section{La importancia de la comunicación emocional}

Pensamos que humanizar la comunicación online es más necesario que nunca en estos tiempos, como ya indicó en la conferencia inaugural del Congreso CIMED Ross Parry, hablando de por qué ahora es el momento para la emoción, la equidad y la comunidad en la tecnología museística. Si no humanizamos la experiencia digital y nos vemos las caras, la comunicación se deshumaniza y pierde su sentido vivencial, incluso su grado de realidad. Por eso creemos que este ha sido uno de los principales motivos del éxito de REMED, la humanización de la comunicación online periódica en un sitio de confianza donde todos nos podemos mirar a los ojos. Aunque aún nos queda un largo camino que recorrer para adaptarnos al nuevo medio.

Somos conscientes de la barrera que todavía supone la tecnología digital para las relaciones sociales digitales. Las enormes carencias de formación que muchos profesionales nos han hecho llegar al respecto, e incluso lo desamparados que se sentían frente a la falta de apoyos para poder formarse adecuadamente.

\section{El papel mediador de la universidad pública}

Por nuestra parte, vimos que desde la universidad pública podíamos asumir un papel de mediadores en este sentido. La Universidad como tantas otras instituciones tiene una obligación de transferencia tecnológica que asumimos con orgullo y esperamos que pueda prolongarse a lo largo del tiempo. De ahí nuestro compromiso para implicar a las empresas, museos e investigadores en proyectos que ayuden a transferir el conocimiento, como estamos haciendo desde la red REMED y el congreso CIMED. De hecho, las actas del congreso se publicarán en abierto, incluyendo las principales contribuciones de conferencias y mesas redondas, junto a los trabajos presentados en las comunicaciones del congreso, más de cincuenta artículos de temáticas variadas, relativas los museos y las estrategias digitales, en los que se tratan temáticas relacionadas con la educación en museos, la accesibilidad, las redes sociales, la museología del futuro, etc. Además, los socios y las socias de REMED pueden consultar los vídeos de las sesiones de los VIERNES REMED anteriores, junto a las entrevistas, o participar en chat de nuestra Intranet. Para hacerse socio/a debe rellenarse un formulario disponible en nuestra página web, es gratuito, y está abierto a profesionales del sector de los museos y las tecnologías digitales.

\section{Un futuro lleno de retos}

En resumen, creemos que REMED y el Congreso de Museos y Estrategias Digitales CIMED pueden llegar a consolidarse como una guía para los profesionales hispanohablantes, que sirva para ir recogiendo las novedades tecnológicas y las estrategias digitales que ayuden a hacer exitosa la enorme tarea de sobrevivir en la compleja situación generada por la COVID19. Pero más allá de la pandemia, cuando esta pase y sea incluso olvidada, el empuje de las nuevas tecnologías seguirá exigiendo una adaptación casi constante tanto de los perfiles profesionales como de la forma de trabajar con los futuros formatos de exposición, tanto presenciales como virtuales, tanto físicos como digitales.

Creemos que esto es solo el punto de inicio de una larga andadura hacia la concreción de una comunidad, la de profesionales e investigadores de museos de lengua hispana, que, hasta ahora, pertenecía más bien al mundo abstracto de los conceptos como una definición de diccionario, para convertirse en algo paradójicamente real gracias al advenimiento de esta época de la comunicación digital donde por fin nos podemos ver todos las caras y sentir que esta comunidad es real, y que tiene la fuerza suficiente para enfrentarnos a un futuro incierto pero seguro apasionante. 